Int. J. Environ. Res. Public Health 2008, 5(1), 41-48

International Journal of

Environmental Research and Public Health

ISSN 1661-7827

www.ijerph.org

(C) 2008 by MDPI

\title{
Vehicle-Dependent Disposition Kinetics of Fluoranthene in Fisher-344 Rats
}

\author{
Deacqunita L. Harris ${ }^{1}$, Darryl B. Hood ${ }^{2}$ and Aramandla Ramesh ${ }^{1 *}$ \\ ${ }^{1}$ Department of Cancer Biology, Meharry Medical College, Nashville, TN 37208, USA \\ ${ }^{2}$ Department of Neurobiology \& Neurotoxicology, Center for Molecular and Behavioral Neuroscience, Meharry Medical \\ College, Nashville, TN 37208, USA \\ *Correspondence to Dr. Aramandla Ramesh: Email: aramesh@mmc.edu
}

Received: 30 October 2007 / Accepted: 29 February 2008 / Published: 30 March 2008

\begin{abstract}
The objective of this study was to evaluate how the vehicles of choice affect the pharmacokinetics of orally administered Fluoranthene [FLA] in rats. Fluoranthene is a member of the family of polycyclic aromatic hydrocarbon chemicals. Fluoranthene exposure to humans may occur as a result of cigarette smoking, consumption of contaminated food and water, heating woods in stoves and boilers, industrial sources such as coal gasification, carbon and graphite electrode manufacturing. Adult male Fisher-344 rats were given single oral doses of 25 and $50 \mu \mathrm{g} / \mathrm{kg}$ FLA in tricaprylin, peanut oil, cod liver oil, tween 80/isotonic saline (1:5) and 2\% Alkamuls-EL620 through gavage. After administration, the rats were housed individually in metabolic cages and sacrificed at 2, 4, 6, 8, 10 and 12 hours post FLA exposure. Blood, lung, liver, small intestine, adipose tissue samples, urine, and feces were collected at each time point. Samples were subjected to a liquid-liquid extraction using methanol, chloroform, and water. The extracts were analyzed by a reverse-phase HPLC, equipped with a fluorescence detector. The results revealed a dose-dependent increase in FLA concentrations in plasma and tissues for all the vehicles used. Plasma and tissue FLA concentrations were greater for peanut oil; cod liver oil, and tricaprylin vehicles compared to Alkamuls $(p<0.05)$, and tween 80/isotonic saline (1:5). Most of the FLA administered through peanut oil, cod liver oil and tricaprylin was cleared from the body by 8 hours $(90 \%)$ and 12 hours $(80 \%)$ post administration for the $25 \mu \mathrm{g} / \mathrm{kg}$ and $50 \mu \mathrm{g} / \mathrm{kg}$ dose groups, respectively. With both doses employed, the metabolism of FLA was highest when cod liver oil was used as a vehicle and lowest in vehicles containing detergent/water [cod liver oil $>$ peanut oil $>$ tricaprylin $>$ alkamuls $>$ tween 80/isotonic saline (1:5)]. These findings suggest that uptake and elimination of FLA is accelerated when administered through oil-based vehicles. The low uptake of FLA from alkamuls and tween 80/isotonic saline may have been a result of the poor solubility of the chemical. In summary, our findings reiterate that absorption characteristics of FLA were governed by the dose as well as the dosing vehicle. The vehicle-dependent bioavailability of FLA suggests a need for the judicious selection of vehicles in evaluating oral toxicity studies for risk assessment purposes.
\end{abstract}

Keywords: Fluoranthene, pharmacokinetics, absorption, tricaprylin, peanut oil, cod liver oil, and alkamuls.

\section{Introduction}

The intestine serves as a barrier between ingested xenobiotic chemicals and digestive enzymes. Physicochemical factors (molecular weight, pKa, lipophilicity, charge/ionization etc.), gastrointestinal (GI) physiologic parameters $(\mathrm{pH})$, dosage, duration of exposure to exogenous chemicals and the carrier (vehicle)-mediated influx and efflux mechanisms may affect the extent of uptake of toxic chemicals from the GI tract $[1,2]$. In oral toxicity studies, compounds that are most frequently used as vehicles are solvents, detergents, and vegetable oils [35]. The vehicles used to deliver the toxic chemicals may influence their systemic absorption, distribution, metabolism, and excretion from the body. Therefore, a detailed knowledge of how the dosing vehicles alter these 
processes will be of paramount importance in interpreting the findings of oral toxicity studies from a regulatory/risk assessment perspective [6,7]. Representative toxicants from different chemical families are used to serve this purpose. One such family of pollutants that enjoy ubiquitous environmental distribution is Polycyclic Aromatic Hydrocarbons (PAHs).

Fluoranthene (FLA) is member of the PAH family of chemicals. This chemical has been classified as a genotoxic agent and a suspected human carcinogen by the International Programme on Chemical Safety [8]. Fluoranthene has been reported to cause lung and liver tumors [9], apoptosis in T-cells [10], decrease in white blood counts, and tubular casts in kidneys [11]. Human exposure to FLA may occur as a result of cigarette smoking, heating woods in stoves and boilers, industrial sources such as coal gasification, iron and steel founding, and living in close proximity to the Superfund hazardous waste sites. Fluoranthene intake through consumption of contaminated food and water far exceed that of inhalation, and dermal exposures [reviewed in 12].

The objective of the present study was to evaluate how the vehicles of choice affect the kinetics of disposition of orally administered FLA in rats. The rationale underlying this investigation is that a relationship exists between the vehicle type and the extent of toxicant solubility in that vehicle, which in turn will affect the intake, metabolism and target organ toxicity.

\section{Materials and Methods}

\section{Chemicals}

Fluoranthene, peanut oil, cod liver oil, tween-80, tricaprylin, sodium dodecyl sulfate (SDS) and halothane were purchased from Sigma Chemical Company (St. Louis, MO). Methanol, chloroform, and ethanol were purchased from Fisher Scientific Company (Kennesaw, GA). Sucrose, EDTA, and tris- $\mathrm{HCl}$ were purchased from Curtin Matheson Scientific Inc. (Houston, TX). Alkamuls EL-620 (polyoxyethylated castor oil) was purchased from Rhone Poulenc Inc. (Westpoint, GA). Labeled ${ }^{3}[\mathrm{H}]$ ) FLA was purchased from Chemsyn Labs (Lenexa, Kansas). Fluoranthene metabolite standards were obtained from the National Cancer Institute Chemical Carcinogen Repository (Midwest Research Institute, Kansas City, MO). As FLA and its metabolite standards are suspected carcinogens and mutagens, they were handled in accordance with NIH guidelines [13].

\section{Animals and Exposure}

Eight-week-old male Fisher-344 rats (Harlan Laboratory, Indianapolis, IN) weighing approximately 200 $\mathrm{g}$ were used in these studies. The animals were housed in a controlled environment $\left(21 \pm 2^{\circ} \mathrm{C}\right.$; humidity $\left.30-70 \%\right)$ in groups of 3 per cage maintained on a $12 / 12 \mathrm{hr}$ light/dark cycle (lights on at $0600 \mathrm{hr}$ ) and allowed free access to rat chow (5001 Lab Meal; Purina Ralston Co.) and water. All animals were allowed a seven-day acclimation period prior to being randomly assigned to a control $(n=6$ per time point) or treatment group ( $\mathrm{n}=6$ per time point).

Treatment consisted of two doses $(25$ and $50 \mu \mathrm{g} / \mathrm{kg})$ of FLA (97\% pure, unlabeled) dissolved in peanut oil, cod liver oil, alkamuls, tricaprilyn, and tween 80/isotonic saline (1:5). These vehicles containing FLA were added to the finely pulverized rat chow mentioned above, and thoroughly mixed. Five milliliters of vehicle was added to one gram of rat chow and kept as a stock solution in an amber colored vial. Depending on the animal weight, the amount (volume) of diet mix (stock) required was calculated for making a working solution and was administered to rats orally via gavage. Before administration, the stock mix was thoroughly stirred to provide homogenous distribution of FLA in the vehicle and prevent settling of test chemical in the vial. Care was taken to ensure that the gavage volume was limited to 1 $\mathrm{ml}$. Animals dosed with FLA in peanut oil were used as positive control. A separate group of animals that received the same vehicle without FLA served as negative control. The above FLA doses were chosen as they represent the concentrations of FLA in food (grilled meat, smoked fish, and sausage; reviewed in [14] and soil from contaminated sites [15].

Sample Collection, Extraction and Processing for FLA Parent Compound/Metabolite Analysis

The animals were food restricted for $12 \mathrm{hrs}$ prior to dosing. Soon after administration, the rats were housed individually in polycarbonate metabolic cages to allow for separate collection of urine and feces. Animals were sacrificed at 2, 4, 6, 8, 10 and 12 hours post-FLA exposure. Blood, organs/tissues of interest were collected at each time point, transferred into cryovials and stored at $-70^{\circ} \mathrm{C}$ until analyzed. Plasma from blood samples was harvested by centrifugation at $2,900 \mathrm{x}$ g for 25 minutes and stored frozen at $-70^{\circ} \mathrm{C}$ until analyzed.

Samples were subjected to a liquid-liquid extraction with water, methanol, and chloroform. The FLA metabolites from the extracts were identified and measured by reverse-phase HPLC with a fluorescence detector as outlined in Walker et al. [16].

\section{Toxicokinetics}

Fluoranthene toxicocokinetic parameters in plasma and lung tissues were analyzed using PK solutions 2.0 (Summit Research Services, Ashland, OH) software. The biological half-life $\left(t_{1 / 2}\right)$ of FLA was calculated by a linear regression of the log plasma concentration versus the time curve. The area under the curve (AUC) was calculated by measuring the area under the blood FLA concentrationtime curve. The mean residence time (MRT) was determined as AUC/AUMC where AUMC is the area under the first moment of curve. The volume of distribution $(\mathrm{Vd})$ was calculated by considering the volume of FLA in the body assuming if present 
throughout the body, FLA remains at the same concentration as in plasma. The total body clearance $(\mathrm{Cl})$ was computed as the ratio of FLA dose and AUC. The elimination rate constant $(\mathrm{Kd})$ was determined as a ratio of $\mathrm{Cl}$ and $\mathrm{Vd}$.

\section{Statistical Analysis}

A multiple analysis of variance (MANOVA) was used for the determination of statistical differences in FLA parent compound/metabolite concentrations in plasma, tissues or excreta at each time point and for each vehicle. All pair wise multiple comparisons were done by Student
Newman-Keuls method. The spearman rank order test was used for correlations in vehicle-induced changes in metabolite levels and toxicokinetic parameters. The criterion for statistical significance was $\mathrm{p}<0.05$ in all cases.

\section{Results}

The results of toxicokinetic studies for FLA are shown in Tables 1-2. The results show that the distribution of FLA in plasma and target tissues was governed by its kinetic parameters.

Table 1: Effect of dosing vehicle on toxicokinetic parameters of $25 \mu \mathrm{g}$ FLA/kg body wt. orally administered to F-344 male rats.

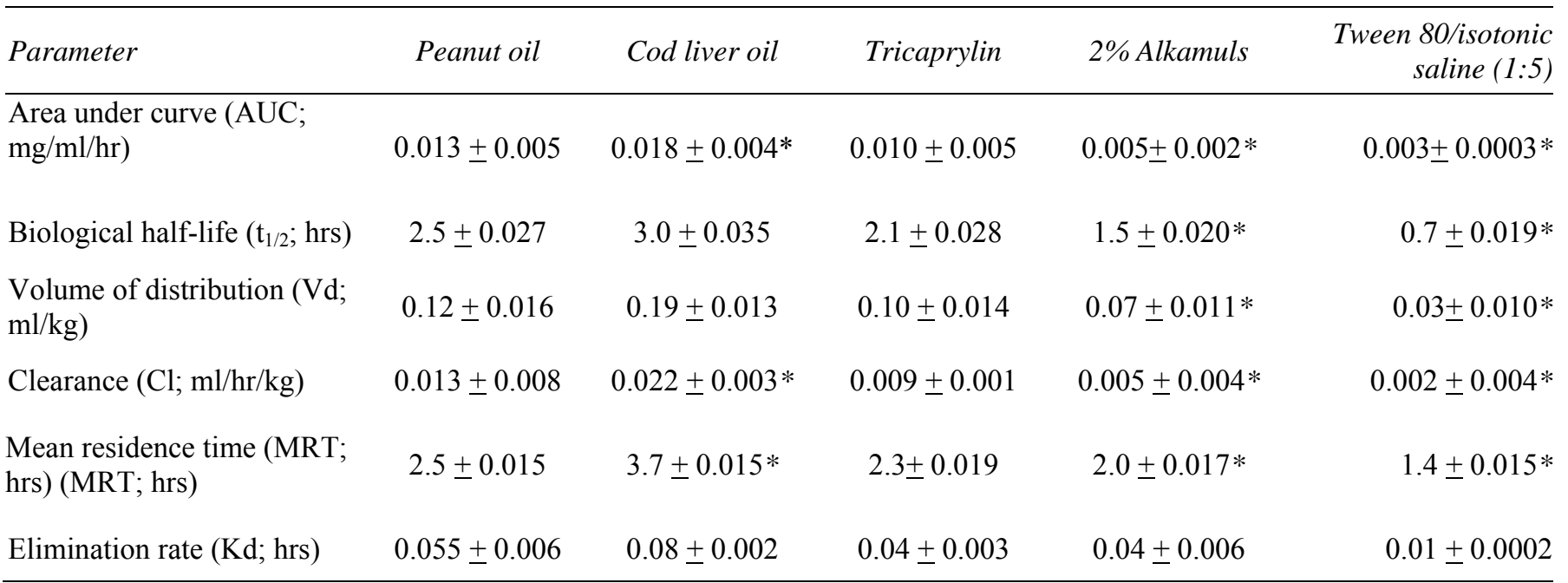

Values represent mean \pm standard error $(n=6)$. *denote statistical significance $(\mathrm{p}<0.05)$ of toxicokinetic parameter values compared to peanut oil vehicle (control).

Table 2: Effect of dosing vehicle on toxicokinetic parameters of $50 \mu \mathrm{g} \mathrm{FLA} / \mathrm{kg}$ body wt. orally administered to F-344 male rats.

\begin{tabular}{|c|c|c|c|c|c|}
\hline Parameter & Peanut oil & Cod liver oil & Tricaprylin & 2\% Alkamuls & $\begin{array}{r}\text { Tween } 80 / \text { isotonic } \\
\text { saline (1:5) }\end{array}$ \\
\hline $\begin{array}{l}\text { Area under curve (AUC; } \\
\mathrm{mg} / \mathrm{ml} / \mathrm{hr} \text { ) }\end{array}$ & $0.018 \pm 0.002$ & $0.025 \pm 0.004^{*}$ & $0.015 \pm 0.005$ & $0.009 \pm 0.003 *$ & $0.005 \pm 0.0003 *$ \\
\hline Biological half-life $\left(\mathrm{t}_{1 / 2} ; \mathrm{hrs}\right)$ & $3.2 \pm 0.031$ & $3.7 \pm 0.035$ & $2.8 \pm 0.028$ & $2.1 \pm 0.020 *$ & $1.3 \pm 0.015^{*}$ \\
\hline $\begin{array}{l}\text { Volume of distribution }(\mathrm{Vd} \\
\mathrm{ml} / \mathrm{kg})\end{array}$ & $0.22 \pm 0.016$ & $0.27 \pm 0.014$ & $0.19 \pm 0.014$ & $0.13 \pm 0.011 *$ & $0.09 \pm 0.010^{*}$ \\
\hline Clearance $(\mathrm{Cl} ; \mathrm{ml} / \mathrm{hr} / \mathrm{kg})$ & $0.020 \pm 0.008$ & $0.031 \pm 0.002 *$ & $0.013 \pm 0.004$ & $0.009 \pm 0.004 *$ & $0.006 \pm 0.004 *$ \\
\hline $\begin{array}{l}\text { Mean residence time (MRT; } \\
\text { hrs) (MRT; hrs) }\end{array}$ & $5.5 \pm 0.015$ & $6.5 \pm 0.013 *$ & $4.8 \pm 0.015$ & $3.8 \pm 0.017^{*}$ & $2.6 \pm 0.015^{*}$ \\
\hline Elimination rate (Kd; hrs) & $0.095 \pm 0.006$ & $0.11 \pm 0.002$ & $0.08 \pm 0.003$ & $0.07 \pm 0.006$ & $0.03 \pm 0.002$ \\
\hline
\end{tabular}

Values represent mean \pm standard error $(n=6)$. *denote statistical significance $(\mathrm{p}<0.05)$ of toxicokinetic parameter values compared to peanut oil vehicle (control). 
The parameters such as volume of distribution $\left(\mathrm{V}_{\mathrm{d}}\right)$, clearance $(\mathrm{CI})$, and elimination rate constant $\left(\mathrm{K}_{\mathrm{d}}\right)$ were lower whereas the mean residence time (MRT) and biological half-life $\left(\mathrm{t}_{1 / 2}\right)$ were higher for FLA administered through cod liver oil vehicle relative to other vehicles. These observations were similar for both doses (25 and 50 $\mu \mathrm{g} / \mathrm{kg}$ ) employed in this study. Within each dose group, the differences in toxicokinetic parameters such as AUC, $\left.\mathrm{t}_{1 / 2}, \mathrm{~V}_{\mathrm{d}}, \mathrm{Cl}\right)$ and MRT were statistically significant $(\mathrm{p}<$ 0.05 ) between cod liver oil and peanut oil; between cod liver oil and 2\% alkamuls; between cod liver oil and tricaprylin. Between the two dose groups, though the values for toxicokinetic parameters showed an increase at $50 \mu \mathrm{g} / \mathrm{kg}$, compared to $25 \mu \mathrm{g} / \mathrm{kg}$, the differences were statistically significant $(p<0.05)$ in the case of $t_{1 / 2}, V_{d}$, and $\mathrm{Cl}$ for FLA administration through cod liver oil.

Disposition kinetics of unmetabolized FLA (FLA parent compound) according to vehicle type is presented in Fig. 1 for $25 \mu \mathrm{g} / \mathrm{kg}$ and Fig. 2 for $50 \mu \mathrm{g} / \mathrm{kg}$.
The disposition of FLA in the body was rapid when administered through lipid-based chemicals such as peanut oil and cod liver oil, compared to tween 80, alkamuls and tricaprylin. With all the vehicles used, unmetabolized FLA was detectable only in plasma, jejunum and feces. Within each dose group, the unmetabolized FLA concentrations were high in intestine, followed by feces and plasma. These differences, however, were not statistically significant. Between the two dose groups, the unmetabolized FLA concentrations showed an increase at $50 \mu \mathrm{g} / \mathrm{kg}$ compared to $25 \mu \mathrm{g} / \mathrm{kg}$ for all vehicles used. When the data are analyzed taking into consideration the vehicle type, at the $25 \mu \mathrm{g} / \mathrm{kg}$ dose, a significant difference is revealed in concentrations of unmetabolized FLA among the different vehicle types. Tricaprylin, peanut oil and cod liver oil vehicles registered high FLA concentrations, compared to tween 80/isotonic saline 1:5 and alkamuls vehicles. A similar trend was seen in the case of $50 \mu \mathrm{g} / \mathrm{kg}$ dose.

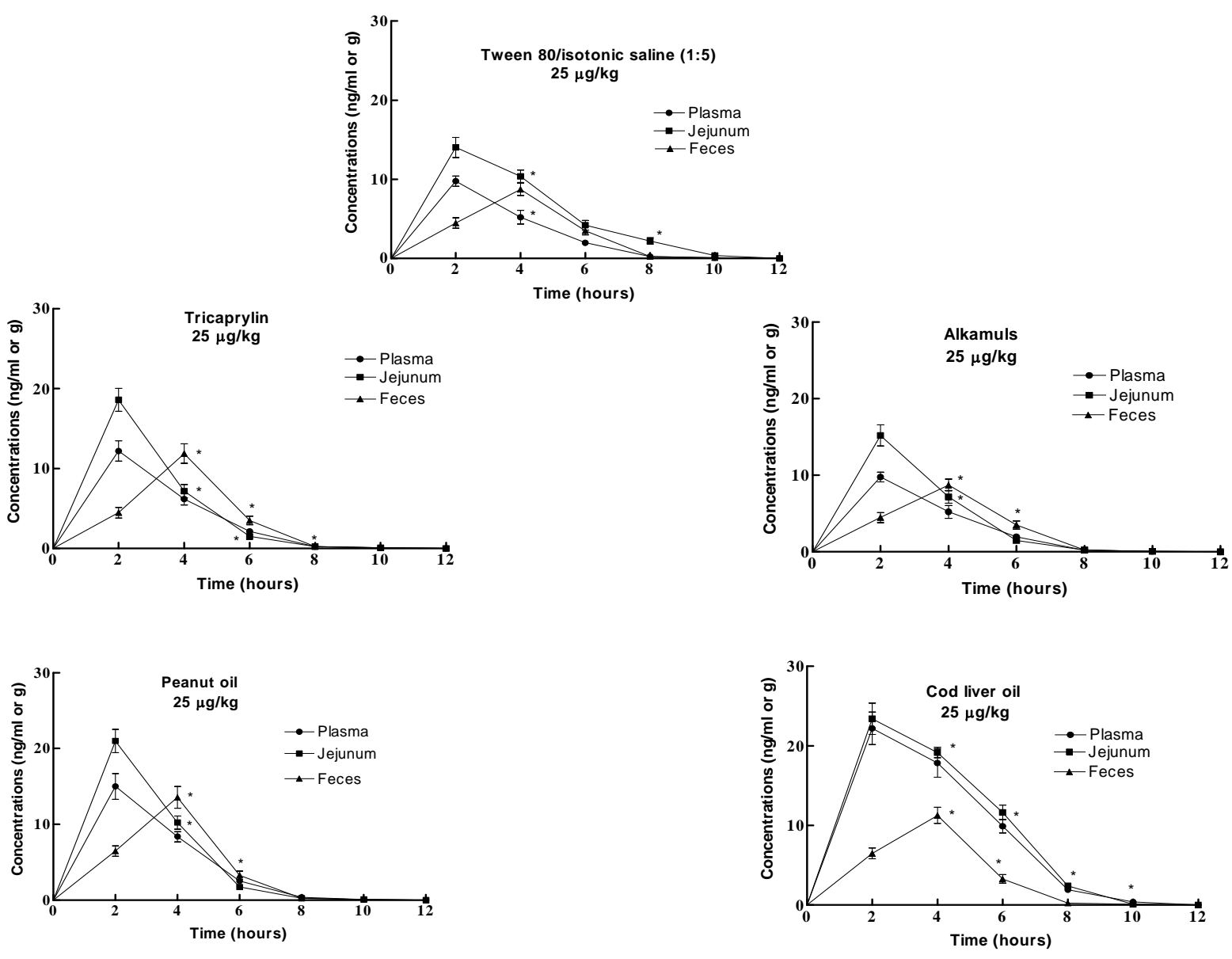

Figure 1: Effect of dosing vehicle on time-course distribution of unmetabolized fluoranthene (FLA) in plasma, jejunum, and feces of F-344 rats that received $25 \mu \mathrm{g}$ FLA/ $\mathrm{kg}$ body wt. via oral gavage. Values represent mean $\pm \mathrm{SE}(\mathrm{n}=6)$. Asterisks denote statistical significance $(p<0.05)$ at the respective time point compared to 2 hour post-exposure. 


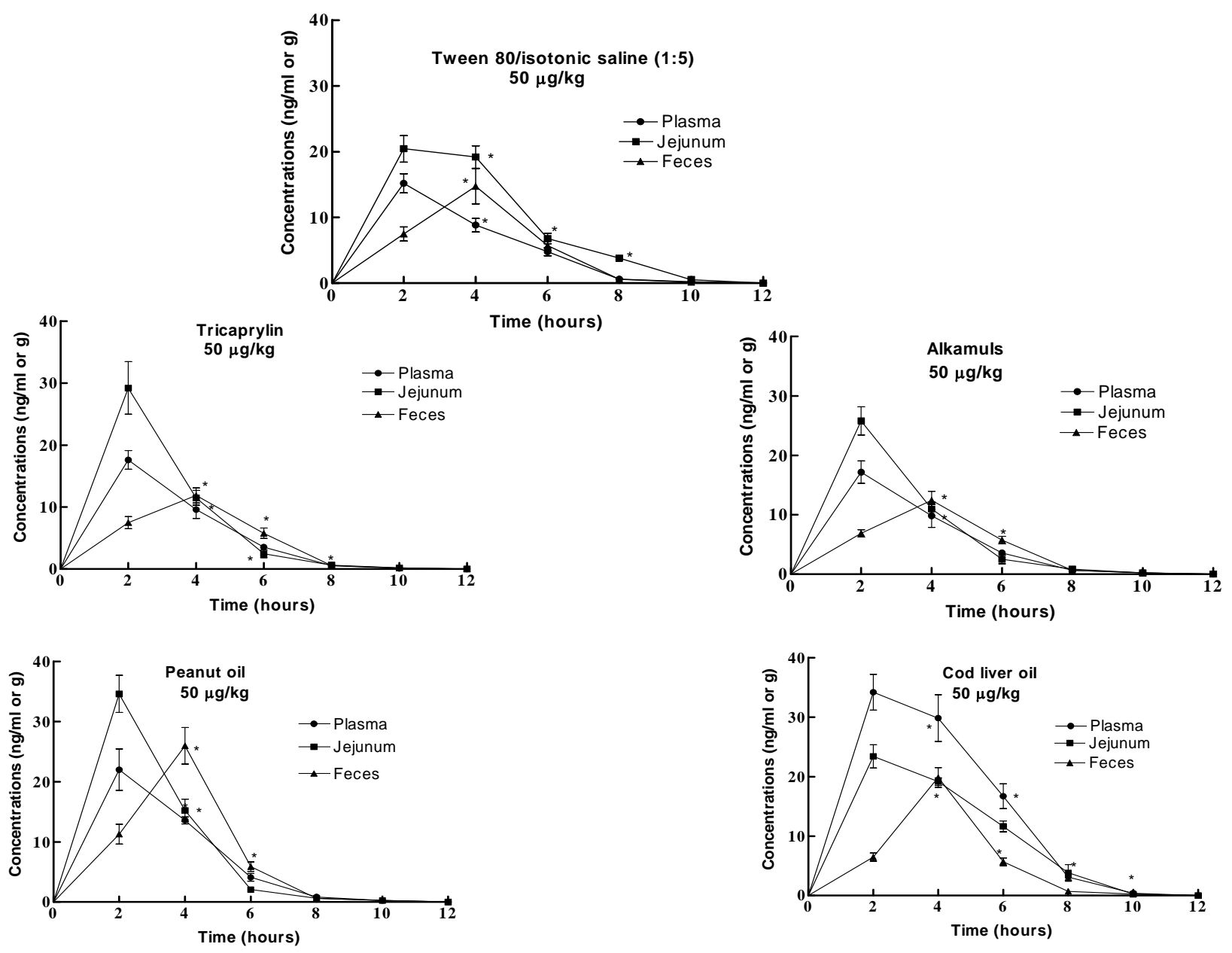

Figure 2: Effect of dosing vehicle on time-course distribution of unmetabolized fluoranthene (FLA) in plasma, jejunum, and feces of F-344 rats that received $50 \mu \mathrm{g} \mathrm{FLA} / \mathrm{kg}$ body wt. via oral gavage. Values represent mean $\pm \mathrm{SE}(\mathrm{n}=6)$. Asterisks denote statistical significance $(p<0.05)$ at the respective time point compared to 2 hour post-exposure.

Most of the FLA parent compound was cleared by 8 hrs, whereas metabolite concentrations detected were 12 hrs post FLA administration. Fluoranthene was considerably metabolized as reflected by the metabolite concentrations that were measured in plasma, target tissues, urine and feces for the 3 types of dietary lipid used at both doses employed. The results for time-course distribution of FLA metabolites in plasma, tissues, urine and feces following oral administration is presented in Fig. 3 for $25 \mu \mathrm{g} / \mathrm{kg}$ and Fig. 4 for $50 \mu \mathrm{g} / \mathrm{kg}$. The metabolite concentrations in urine and feces showed a gradual increase, reaching a peak between 4 and 6 hours postexposure and decreased thereafter. The metabolite concentrations in plasma and tissues peaked at 4 hours post-exposure, regardless of the vehicle type used. At both doses employed, the metabolism of FLA was highest when cod liver oil was used as a vehicle and lowest in vehicles containing detergent/water [cod liver oil $>$ peanut oil $>$ tricaprylin $>$ alkamuls $>$ tween 80/isotonic saline (1:5); treatment $\mathrm{X}$ vehicle interaction, $\mathrm{p}<0.005$ ].
The following were the predominant metabolites identified i) trans-2,3-Dihydrohydroxy fluoranthene (Fluoranthene-trans-2,3-dihydrodiol) ii) trans-2,3dihydroxy-1,10b-epoxy-1,2,3,10b-tetrahydrofluoranthene (2,3 DFLA) iii) Fluoranthene-2,3-dione iv) 3hydroxyfluoranthene and v) 8-hydroxyfluoranthene (putatively identified). The former three are reactive metabolites and the latter two are detoxification products. The percentage composition of individual metabolite types among the total metabolites varied according to the dosing vehicle type. When vehicles like tween 80 , tricaprylin, and alkamuls were used, the proportions of hydroxy (3-and 8hydroxy) metabolites were greater than the other metabolites. On the other hand, the concentrations of FLA-2, 3-dihydrodiol; 2, 3-DFLA and 2, 3-dione were greater than the hydroxy metabolites when peanut and cod liver oil were used as vehicles. However, the differences were not statistically significant with respect to the dose and vehicle type. 


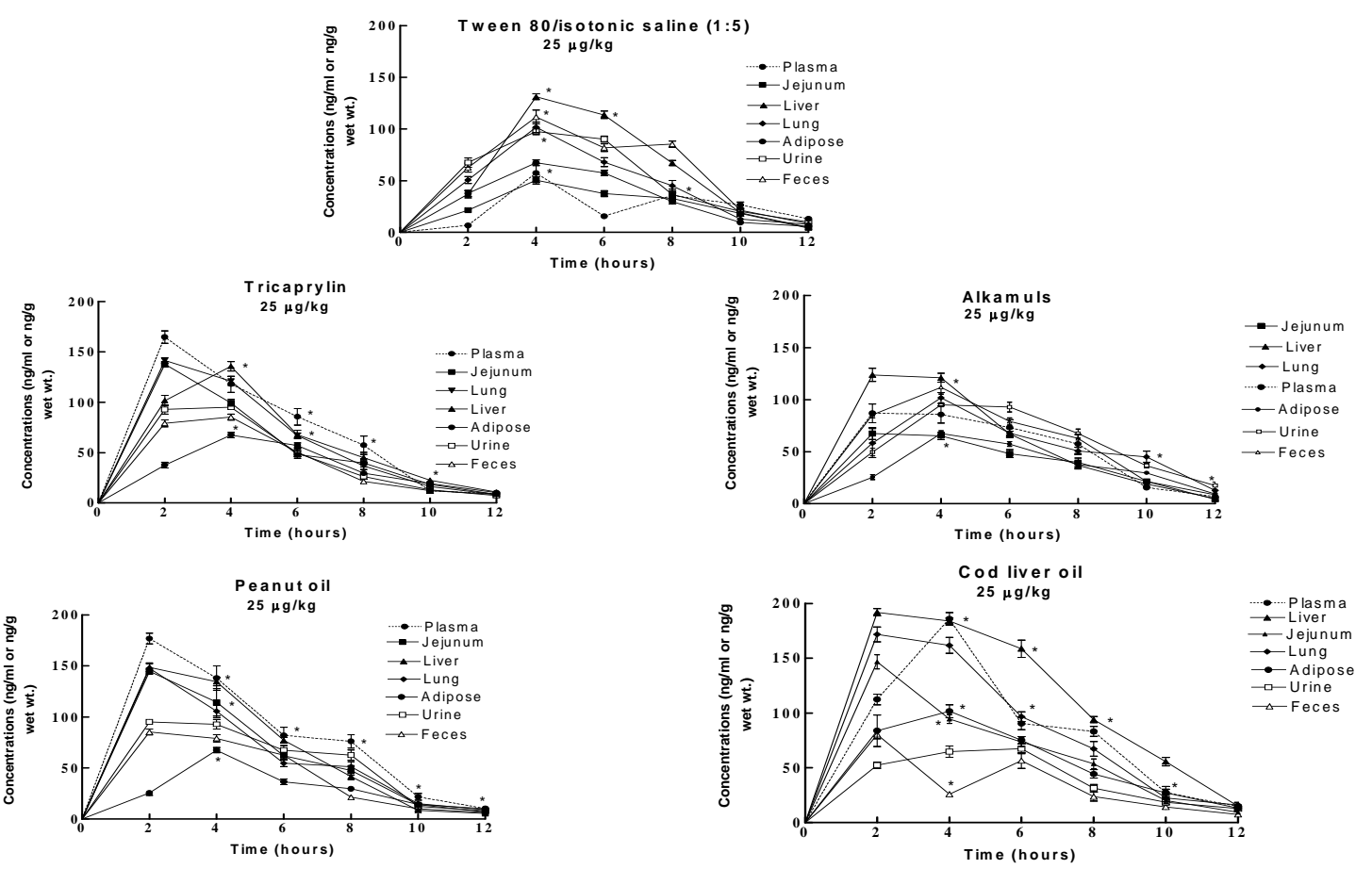

Figure 3: Effect of dosing vehicle on time-course distribution of fluoranthene (FLA) metabolite concentrations in plasma, jejunum, feces, liver, lung, adipose, urine and feces of F-344 rats that received $25 \mu \mathrm{g} \mathrm{FLA} / \mathrm{kg}$ body wt. via oral gavage. Values represent mean \pm SE $(n=6)$. Asterisks denote statistical significance $(p<0.05)$ at the respective time point compared to 2 hour post-exposure.
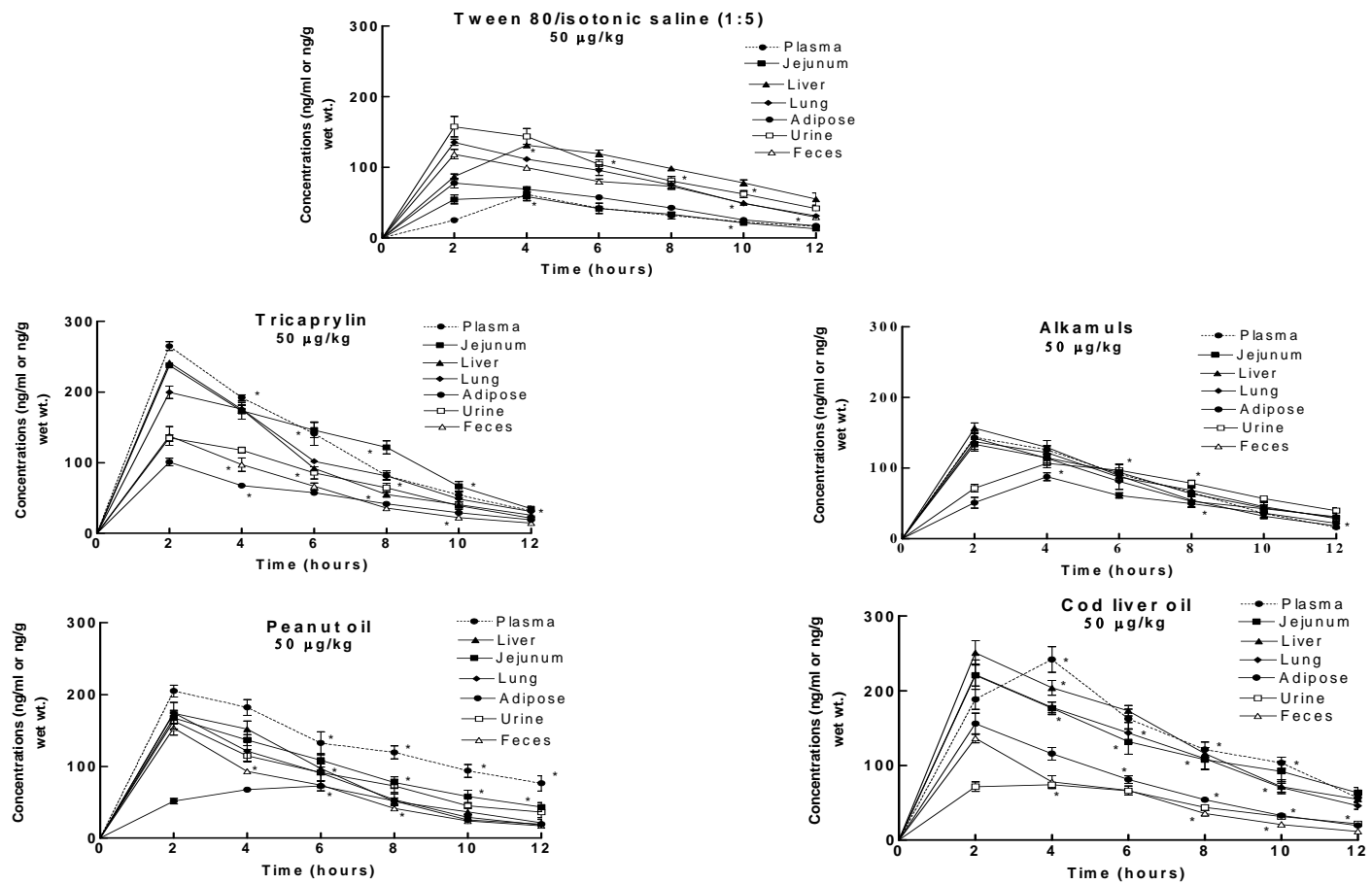

Figure 4: Effect of dosing vehicle on time-course distribution of fluoranthene (FLA) metabolite concentrations in plasma, jejunum, feces, liver, lung, adipose, urine and feces of F-344 rats that received $50 \mu \mathrm{g}$ FLA/kg body wt. via oral gavage. Values represent mean \pm SE $(n=6)$. Asterisks denote statistical significance $(p<0.05)$ at the respective time point compared to 2 hour post-exposure. 


\section{Discussion}

Though most of the ingested FLA was metabolized and excreted, some of the unchanged parent compound was detected in plasma, intestine, and feces. It is not uncommon for any orally ingested chemical compound, that the unmetabolized component is transported into the lumen of the GI tract and eliminated through feces. Similar to the present study, several other studies have reported unchanged PAHs such as $\mathrm{BaP}$ [17], chrysene [18] and pyrene [19] in rats orally exposed to these chemicals. The differences in the levels of unchanged FLA among the vehicles noticed in the present study suggests that the presence of unchanged FLA depend on the bioavailability of the administered dose and lipid content in the vehicle. Between the two oil-based vehicles, the low residence time and high clearance values for FLA in peanut oil indicate that this toxicant is rapidly bioavailable to organs. On the other hand, the high residence time and low clearance values for FLA in cod liver oil relative to peanut oil (a vehicle that represents monounsaturated fat) reflect delays in the elimination of FLA ingested through cod liver oil (a vehicle that represents polyunsaturated fat). Because the absorption of PAHs is promoted by concurrent lipid absorption in the intestine [20], the high dose of FLA administered may have caused a poor extraction of FLA by the gastrointestinal fluids and a capacity limited absorption and biotransformation [21] eventually contributing to the unmetabolized FLA levels.

Notwithstanding the presence of unmetabolized FLA in plasma, intestine and feces, a considerable amount of the metabolized dose is bioavailable when FLA is administered through peanut- and cod liver oils. The relatively high solubility and less lipophilicity of metabolites (compared to the parent compound) facilitate the transport of the metabolized FLA to the target tissues through systemic circulation. The presence of a significant difference among various vehicles in residence time as well as clearance of FLA suggests that FLA administered through these vehicles have different elimination characteristics.

The high FLA metabolite concentrations that were realized more with cod liver oil compared to peanut oil and alkamuls could be due to the degree of lipid saturation. Peanut oil is a monounsaturated fat whereas cod liver oil is a polyunsaturated fat [22]. Fluoranthene has a tendency to be absorbed rapidly through saturated fat and its residence time in tissues was found to be high relative to that given through monounsaturated fat. Studies conducted by other investigators [23, 24] also found that the uptake of lipophilic environmental toxicants such as dioxins, furans and aliphatic nitriles through the GI tract is facilitated by the use of oils as dosing vehicles. Findings from the present study demonstrate that the solubility of FLA in the oil-based vehicles used may have contributed to an increased delivery of the test chemicals to target tissues. In this context, it is worth mentioning that most of the oil-based vehicles were reported to reduce intragastric mobility and delay gastric emptying [25]. The secondary peak concentrations of FLA metabolites measured in some tissues is indicative of a pulsatile uptake of ingested FLA. The pulsatile uptake can be attributed to fractional gastric emptying, because the administered dose is divided into aliquots in the lipid globules [26] by associating with chylomicrons [27] that may be differently absorbed from different segments of the GI tract [28]. Also, the high concentrations of FLA parent compound and metabolites recorded in tricaprylin compared to Tween 80 may be due to their chemical nature. While Tween 80 is a nonionic surfactant, tricaprylin is a vegetable oil-based formulation containing some amount of natural fatty acid and glycerin. In the present study Tween 80 was mixed with isotonic saline at a ratio of 1:5. Thus, it has a detergent and a water base compared to the fatty acid nature of tricaprylin that may have contributed to the differences in FLA disposition characteristics. In regards to alkamuls, it appears to be a vehicle of limited choice as the disposition of FLA administered through this vehicle is low. Findings of our studies are in line with that of other researchers who reported that alkamuls-dependent bioavailability was low for a diverse group of chemicals such as chloroform [29] and deltamethrin [7].

The absence of a marked difference in the relative concentrations of various metabolites among the different vehicles employed suggests that the vehicle type influences significantly the quantitative distribution of metabolites, without affecting the qualitative profile. Perhaps, the different FLA metabolite types produced are largely a measure of the biotransformation of FLA. The vehicle-dependent bioavailability and disposition kinetics seem to be influenced by the solubility and interaction among FLA and the respective vehicle and transport processes across the intestinal membrane. In conclusion, peanut and cod liver oils may serve as vehicles of choice for administering FLA for oral toxicity studies. The findings from this study will also provide a basis for conducting subchronic studies to test the efficacy of vehicles because data from long-term toxicity studies using animal models will be of use for risk assessment purposes.

Acknowledgements: This research was supported in part by a Center of Excellence grant to Meharry Medical College from the U.S. Health Resources and Services Administration (D34HP00003), and National Institutes of Health grants, 1R15ES012168, 1RO3CA130112-01 (AR), S11ES014156-01 (DBH \& AR), G12RRO3032 (Meharry), and 5T32HL007735-12 (DLH).

\section{References}

1. Dolusio, J. T.; Tan, G. H.; Billups, N. F.; Diamond, L.: Drug absorption. II. Effect of fasting on intestinal drug absorption. J. Pharmacol. Sci., 1969, 58, 12001202.

2. Balimane, P. V; Chong, S; Morrison, R. A.: Current methodologies used for evaluation of intestinal 
permeability and absorption. Journal of Pharmacol. and Toxicol. Methods, 2000, 44, 301-312.

3. Gad, S. C.; Chengelis, C. P.: Acute toxicology of testing perspectives and horizons. Caldwell, N. J.: Telford Press, 1988.

4. O'Hara, T. M.; Borzelleca, J. F.; Clarke, E. C.; Sheppard, M. A.; Condie, L. W. A.: $\mathrm{CCl}_{4} / \mathrm{CHCl}_{3}$ interaction study in isolated hepatocytes: selection of a vehicle. Fundam. Appl. Toxicol., 1989, 13, 605-615.

5. Braak, K.; Frey, H.-H.: Effects of solvents and detergents on the contractions of isolated smooth muscle preparations. J. Pharm. Pharmacol., 1990, 42, 837-841.

6. Gad, S. C.; Cassidy, C. D.; Aubert, N.; Spainhour, B.; Robbe, H.: Nonclinical vehicle use in studies by multiple routes in multiple species. Int. J. Toxicol., 2006, 25, 499-521.

7. Kim, K. B.; Anand, S. S.; Muralidhara, S.; Kim, H. J.; Bruckner, J. V.: Formulation-dependent toxicokinetics explains differences in the GI absorption, bioavailability and acute neurotoxicity of deltamethrin in rats. Toxicology, 2007, 234, 194-202.

8. IPCS. Environmental Health Criteria 202: Selected non-heterocyclic polycyclic aromatic hydrocarbons. International Programme on Chemical Safety, Lyon, France: World Health Organization, 1998.

9. Wang, J. S.; Busby, W.F. Jr.: Induction of lung and liver tumors by fluoranthene in a preweanling CD-1 mouse bioassay. Carcinogenesis, 1993, 14, 18711874.

10. Yamaguchi, K.; Near, R.; Shneider, A.; Cui, H.; Ju, ST.; Sherr, D. H.: Fluoranthene-induced apoptosis in murine $\mathrm{T}$ cell hybridomas is independent of the aromatic hydrocarbon receptor. Toxicol. Appl. Pharmacol., 1996, 139, 144-152.

11. Knuckles, M.; Inyang, F.; Ramesh, A.: Acute and subchronic oral toxicity of fluoranthene in F-344 rats. Ecotoxicol. Environ. Saf., 2004, 59, 102-108.

12. Walker, S. A.: Effects of dietary fat on the metabolism of fluoranthene: an environmental toxicant. Ph.D. Thesis, Meharry Medical College, 2005, 138pp.

13. NIH. Guidelines for the laboratory use of chemical carcinogens. NIH Publication No. 81-2385, Washington, DC: National Institutes of Health, U.S. Government Printing Office; 1981.

14. Ramesh, A.; Walker, S. A.; Hood, D. B.; Guillén, M. D.; Schneider, K.; Weyand, E. H.: Bioavailability and risk assessment of orally ingested polycyclic aromatic hydrocarbons. Int. J. Toxicol,, 2004, 23, 301-33.

15. Hu, J.; Zhang, G.; Liu, C.-Q.: Pilot study of polycyclic aromatic hydrocarbons in surface soils of Guiyang city, People's Republic of China. Bull. Environ. Contam. Toxicol., 2006, 76, 80-89.

16. Walker, S. A.; Addai, A. B.; Mathis, M.; Ramesh, A.: Effect of dietary fat on metabolism and DNA adduct formation after acute oral exposure of F-344 rats to fluoranthene. J Nutr Biochem., 2007, 18, 236249.
17. Ramesh, A.; Inyang, F.; Hood, D. B.; Archibong, A. E.; Knuckles, M. E.; Nyanda, A. M.; Metabolism, bioavailability, and toxicokinetics of benzo[a]pyrene $[\mathrm{B}(\mathrm{a}) \mathrm{P}]$ in $\mathrm{F}-344$ rats following oral administration. Exp Toxic Pathol., 2001, 53, 253-270.

18. Grimmer, G.; Brune, H.; Dettbarn, G.; Heinrich, U.; Jacob, J.; Mohatashamipur, E., Norpoth, K.; Pott, F.; Wenzel-Hartung, R.: Urinary and faecal excretion of chrysene and chrysene metabolites by rats after oral, intraperitoneal, intratracheal or intrapulmonary application. Arch. Toxicol., 1988, 62, 401-405.

19. Jacob, J.; Brune, H.; Dettbarn, G.; Grimmer, D.; Heinrich, U.; Mohatashamipur, E.; Norpoth, K.; Pott, F.; Wenzel-Hartung, R.: Urinary and faecal excretion of pyrene and hydroxypyrene by rats after oral, intraperitoneal, intratracheal or intrapulmonary application. Cancer Lett., 1989, 46, 15-20.

20. Rahman, A.; Barrowman, J. A.; Rahimtula, A.: The influence of bile on the bioavailability of polynuclear aromatic hydrocarbons from the rat intestine. Can. J. Physiol. Pharmacol., 1986, 64, 1214-1218.

21. Laher, J. M.; Rigler, M. W.; Vetter, R. D.; Barrowman, J. A.; Patton, J. S.: Similar bioavailability and lymphatic transport of benzo(a)pyrene when administered to rats in different amounts of dietary fat. Journal of Lipid Research, 1984, 25, 1337-1342.

22. Holland, B.; Welch, A. A.; Unwin, I. D.; Buss, D. H.; Paul, A. A.; Southgate, D. A. T.: McCance and Widdowson's - The Composition of Foods, Cambridge (England), The Royal Society of Chemistry, 1992, p. 462.

23. van den Berg, M.; Sinke, M.; Wever, H.: Vehicledependent bioavailability of polychlorinated dibenzop-dioxins (PCDDs) and -dibenzofurans (PCDFs) in the rat. Chemosphere, 1987, 16, 1193-1203.

24. Farooqui, M. Y.; Ybarra, B.; Piper, J.; Tamez, A.: Effect of dosing vehicle on the toxicity and metabolism of unsaturated aliphatic nitriles. J. Appl. Toxicol., 1995, 15, 411-420.

25. Palin, K. J.; Whalley, D. R.; Wilson, C. G.; Davis, S. S.; Phillips, A. J.: Determination of gastric-emptying profiles in the rat: Influence of oil structure and volume. Int. J. Pharmacol., 1982, 12, 315-322.

26. Kim, H. J.; Bruckner, J. V.; Dallas, C. E.; Gallo, J. M.: Effect of dosing vehicles on the pharmacokinetics of orally administered carbon tetrachloride in rats. Toxicol. Appl. Pharmacol., 1990, 102, 50-60.

27. Gershkovich, P.; Hoffman, A.: Uptake of lipophilic drugs by plasma derived isolated chylomicrons: linear correlation with intestinal lymphatic bioavailability. Eur J Pharm Sci., 2005, 26, 394-404.

28. Withey, J. R.; Collins, B. T.; Collins, P. G.: Effect of vehicle on the pharmacokinetics and uptake of four halogenated hydrocarbons from the gastrointestinal tract of the rat. J. Appl. Toxicol., 1983, 3, 249-253.

29. Dix, K. J.; Kedderis, G. L.; Borghoff, S. J.: Vehicledependent oral absorption and target tissue dosimetry of chloroform in male rats and female mice. Toxicol. Lett., 1997, 91, 197-209. 